\title{
Role of IGFs and Insulin in the Human Testis During Postnatal Activation: Differentiation of Steroidogenic Cells
}

\author{
ESPERANZA B. BERENSZTEIN, MARÍA S. BAQUEDANO, CAROLINA M. PEPE, MARIANA COSTANZO, NORA I. SARACO, \\ ROBERTO PONZIO, MARCO A. RIVAROLA, AND ALICIA BELGOROSKY
}

Endocrine Service [E.B.B., M.S.B., C.M.P., M.C., N.I.S., M.A.R., A.B.], Hospital de Pediatria Garrahan, Buenos Aires C1245 AAM, Argentina; Instituto de Investigaciones en Reproducción [R.P.], Universidad de Buenos Aires, Buenos Aires C1121ABG, Argentina

\begin{abstract}
Immunoexpression of IGF-I, IGF-II, type 1 IGF receptor (IGFR), insulin receptor (IR), and GH receptor (GHR) was analyzed in human testis, in three age groups (Gr): Gr1 (neonates), Gr2 (postnatal testicular activation), and Gr3 (early prepuberty). In interstitial cells, low IGF-I and GHR, but moderate IR immunoexpression was observed in all Grs. However, high expression of IGF-II in $\mathrm{Gr} 1$, and moderate expression of IGFR in Gr1 and Gr2 were found. In Leydig cell (LC), high expression of IGF-II, moderate expression of IGFR and GHR, and undetectable IGF-I was found. Moreover, IR was highly expressed in Gr2. The effect of IGF-I on cell proliferation (PI) and apoptosis (AI), induction of cytochrome P450 side chain cleavage (cP450scc) immunoexpression, 3 $\beta$-hydroxysteroid dehydrogenase mRNA and testosterone $(\mathrm{T})$ secretion was evaluated in human testis cell cultures. IGF-I increased P450scc immunoexpression, $3 \beta$-hydroxysteroid dehydrogenase mRNA, T secretion, and PI, but decreased AI. We propose that IGF-II, mainly through IR, is involved in functional LC differentiation. In some interstitial cells, probably in LC precursors, IGF-II/IR could be involved, among other factors, in the stimulation of PI and/or inhibition of AI, and in LC differentiation. (Pediatr Res 63: 662-666, 2008)
\end{abstract}

$\mathrm{T}$ hree growth phases of Leydig cell (LC) differentiation and activation have been described in humans (1). Fetal LCs produce testosterone $(\mathrm{T})$, required for fetal masculinization, and insulin-like growth factor-3, necessary for testicular descent (2). Fetal LCs regress gradually during the third trimester of pregnancy. A second wave of infantile LCs has been described during the postnatal surge of LH/T, in the first trimester of postnatal life (3). Finally, the last wave of adult LCs coincides with pubertal development. Prince (4) has described that fetal LCs show various degrees of involution until birth. In neonates, the dominant cell types in the interstitium are fibrocytes and mesenchymal fibroblasts, although occasional LCs can persist. It has been proposed that postnatal LC development restarts either from the mesenchymal fibroblasts or from the previously regressed LCs $(1,5)$. Furthermore, even though the infantile phase of LC development might be dependent on the reactivation of the hypothalamo-

Received September 24, 2007; accepted January 30, 2008.

Correspondence: Alicia Belgorosky, M.D., Ph.D., Endocrine Service, Hospital de Pediatría Garran, C. de los Pozos 1881, Buenos Aires, C1245 AAM, Argentina; e-mail: abelgo@elsitio.net

This work was supported by grants from Consejo Nacional de Investigaciones Cientıficas y Tecnicas (CONICET), Fondo para la Investigacion Cientıfica y Tecnológica (FONCYT) of Argentina, and Pfizer Endocrine Care. pituitary-testicular axis, the molecular mechanisms involved remain unclear.

There are some indirect evidences that the GH-IGF (IGF) axis might be involved in preserving precursor and immature LC pools, as well as in the modulation of local steroidogenesis (6). In an IGF-I KO mice model, Baker et al. (7) found a reduced number of mature LCs, and Wang et al. $(8,9)$ reported that IGF-I was a critical factor in the control of adult LC number and LC maturation. It has also been proposed that $\mathrm{LH}$ was not a direct mitogenic factor to LCs, and the presence of IGF-I was required. In addition, it has been published that IGFs increase proliferation and differentiation of rodent LC precursors, as well as the steroidogenic response to $\mathrm{LH}$, in fetal and adult LCs in culture (10).

Patients with isolated GH deficiency or insensitivity show small testes, delayed puberty and low response to human chorionic gonadotropins $(11,12)$, suggesting that the GH-IGF system is required for adequate $\mathrm{T}$ synthesis, at least, in immature testes. Along this line, $\mathrm{GH}$ administration evokes an increase in the number of precursor mesenchymal cells in the testis of immature hypophysectomized male rats (13), as well as increments in the expression of several steroidogenic enzymes in precursor immature LCs. Hence, a role of the GH-IGF system on precursor LC differentiation has been proposed (14). Furthermore, even though GH receptor (GHR) mRNA expression has been detected in human testicular tissue (15), its immunolocalization in human prepubertal testis has not been determined. In addition, it has been recently demonstrated that IGF-II is able to regulate steroidogenesis in rat LCs (16). Therefore, a role for either IGF-I or IGF-II on precursor or immature LC differentiation, via IGF receptor (IGFR), could be proposed. Moreover, even though it has been described that IGFR is expressed in rat and mouse LCs, little is known about its immunolocalization in the interstitial cells (IC) of immature human testes.

The insulin-signaling pathway is essential in many tissues, not only for glucose uptake but also in the activation of mitogenic processes (17). As described for other tissues, it

Abbreviations: 3ßHSD, $3 \beta$-hydroxysteroid dehydrogenase; Ab, antibody; GHR, growth hormone receptor; Gr, Group; IC, interstitial cells; IGFR, type 1 IGF receptor; IR, insulin receptor; LC, Leydig cell; rhIGF-I, recombinant human type 1 insulin-like growth factor; $\mathbf{T}$, testosterone 
could be proposed that the insulin-signaling pathway might also contribute to the molecular mechanisms behind LC precursor proliferation and/or LC functional differentiation.

Recently, we have proposed that local production of $\mathrm{T}$ by steroidogenic precursor cells or remaining fetal LC of neonates, probably acting through peritubular or IC, might be one of the factors involved in the induction of infantile LC differentiation (18). In this work, we have analyzed (1) IGF-I, IGF-II, IGFR, insulin receptor (IR), and GHR immunoexpression and localization in human prepubertal testicular tissue, at different prepubertal phases of LC development, and (2) the effect of chronic recombinant human IGF-I (rhIGF-I) administration during culture, on human prepubertal testicular somatic cell apoptosis and proliferation, as well as on $\mathrm{T}$ secretion, induction of $\mathrm{cP} 450 \mathrm{scc}$ immunoexpression, and $3 \beta$-hydroxysteroid dehydrogenase ( $3 \beta \mathrm{HSD}$ ) mRNA.

\section{MATERIALS AND METHODS}

Clinical material. Human prepubertal testes were collected at necropsy from patients who died of disorders not related to endocrine or metabolic diseases. Cadavers were placed at $4^{\circ} \mathrm{C}$ within $1 \mathrm{~h}$ after death. Necropsies were carried out within the following $12 \mathrm{~h}$. In every case, written consent from the closest relatives had been obtained. The study was approved by the Institutional Review Board of the Garrahan Pediatric Hospital. Thirty-two testes from prepubertal subjects, aged $1 \mathrm{~d}$ to $3 \mathrm{y}$ were studied. As published before $(18,19)$, samples were divided in three age groups (Grs): Gr1, newborns (1- to 21-d-old neonates, $n=11$ ); Gr2, postnatal activation stage (1- to 7-mo-old infants, $n=11$ ); Gr3, early childhood (12- to 60-mo-old boys, $n=10$ ). Death was secondary to multiple diseases in every group of subjects, but congenital cardiac malformation was responsible for death in approximately $80 \%$ of cases of $\mathrm{Gr} 1$ and in $40 \%$ of Gr2. Pneumonia (one sample), sepsis (two samples), encephalopathy (one sample), and intestinal malformation in $\mathrm{Gr} 3$ samples were other diagnoses. Testes collected at necropsy were fixed in $4 \%$ formalin/PBS and embedded in paraffin, or/and processed for cell isolation and culture.

IGF-I, IGF-II, IGFR, IR, and GHR immunoexpression in testicular cells. Tissue sections were incubated with the following antibodies (Abs): a primary rabbit polyclonal $\mathrm{Ab}$ raised against rhIGF-I (GroPep code P MAb $\mathrm{AB}-\mathrm{Ca}$, Adelaide, Australia); a rabbit polyclonal Ab raised against rhIGF-II (aa 78-180) (sc-5622, Santa Cruz Biotechnology Inc., Santa Cruz, CA); an anti- $\alpha$ IGFR MAb (MAB1120, Chemicon International, Temecula, CA), showing no cross-reaction with IR; MAb to GHR (G9000-16, US Biologic, Swampscott, MA); and a rabbit polyclonal Ab to IR (sc-710; Santa Cruz Biotechnology). As secondary Ab, either biotinylated goat anti-rabbit (IGF-I, IGF-II, and IR) or biotinylated rabbit anti-mouse (IGFR and GHR) immunoglobulins were used. All primary antibodies had been used in studies published in multiple journals.

As previously described (18), staining was performed using the streptavidin-biotin and peroxidase method, using the manufacturer's protocol (DAKO Catalyzed Signal Amplification System, HRP, DAKO Cytomation, Carpinteria, CA).

As negative controls, normal rabbit serum (for IGF-I, IGF-II, and IR) or normal mouse serum (for IGFR and GHR) was used instead of primary Ab. No specific immunoreactivity was detected in these sections. Immunostudies were repeated twice, and no difference in the pattern of immunolocalization was detected between the two samples. Porcine hepatic tissue was used as positive control.

To evaluate LC immunostaining, and to better recognize cell type, an additional preparation with hematoxylin/eosin (H\&E) staining was used. Occasionally, combined immuno and H\&E staining was performed for a better identification of LC.

Testicular cells were counted in single sections using a Carl Zeiss Axiovision microscope under a $100 \times$ objective lens. Approximately, $300 \mathrm{IC}$ and peritubular cells per each slide, was counted. For quantification, a modification of the proportionate score of Allred (20) was used as follows: after the mean number of positive cells per 100 total cells was calculated per subject, a Gr mean was calculated (except for LC, as explained) (18). A mean of less than $1 \%$ was considered as negative $(-), \geq 1-5$ as,$\pm \geq 5-20$ as,$+ \geq 20-35$ as ++ , and $\geq 35-50$ as +++ .
Primary culture of human prepubertal testicular somatic cellsstimulation with rhIGF-I. A sample of the testicular testes was dissected and double digested as previously described (21). Cells were seeded in DMEM/ Ham F12 supplemented with $5 \mathrm{mg} / \mathrm{mL}$ vitamin C, $0.2 \mu \mathrm{g} / \mathrm{mL}$ vitamin E, and $10 \%$ FCS during the first $48 \mathrm{~h}$. Germ cells are lost during this procedure. Then, the somatic cell layer is washed and fresh serum-free medium, containing rhIGF-I $(50 \mathrm{ng} / \mathrm{mL}$ ) or not (basal conditions) was added during two consecutive 48 -h periods (chronic stimulation). Conditioned media of culture $\mathrm{d} 6$ were stored at $-20^{\circ} \mathrm{C}$, and T secreted to the medium was measured under basal and stimulated conditions. Furthermore, P450scc and Ki-67 antigen immunochemistry, as well as estimation of apoptosis, was carried out on the cell layer.

On d 1 of culture, cells are organized in clusters surrounded by isolated dispersed cells (21). During the following days, a layer of cells grows out from cell aggregates to reach an almost confluent layer, spreading among clusters. Specific staining indicated that the intercluster layer was composed of IC (21).

Detection of apoptosis and cell proliferation in cell cultures. Cell apoptosis and cell proliferation was carried out according to previous report (19). Briefly, apoptosis was detected using the DeadEnd Colorimetric Apoptosis Detection System (Promega Corp., Madison, WI). Positive nuclei stain brown while nonapoptotic nuclei stain blue. To detect proliferating cells, a mouse $\mathrm{MAb}$ anti-Ki-67 (Dako Corporation, Clone Ki-S5, Code No. M 7187) was used. Positive nuclei from cycling cells were stained brown. A minimum of 400 monolayer cells was counted. The AI and the PI were calculated as the percentage of positive cells.

Testosterone secretion during cell cultures. $\mathrm{T}$ was determined in conditioned medium by a solid-phase RIA, based on testosterone-specific antibody immobilized on the wall of a polypropylene tube. $\mathrm{I}^{125}$-labeled testosterone competed for a fixed time with testosterone in the sample for antibody sites (Coat-a-Count; DPC, Los Angeles, CA). Minimal detectable dose was 0.14 $\mathrm{nmol} / \mathrm{L}$. Intraassay imprecision profile was below $10 \%$ between 0.14 and 55.5 $\mathrm{nmol} / \mathrm{L}$. Values were corrected for harvested trypan blue-negative cells and for time since last change of medium (usually $48 \mathrm{~h}$ ), to be expressed in $\mathrm{pmol} / 10^{6}$ cells $\times 24 \mathrm{~h}$. Adequate parallelism with standards was found at three different dose levels in two samples, in duplicate. $\mathrm{T}$ secretion to conditioned media was assayed at d 6 of culture, after $96 \mathrm{~h}$ of only medium (basal conditions) or chronic rhIGF-I stimulation. The effect of rhIGF-I on T secretion, calculated as before, was expressed as \% of its own basal, and differences were analyzed using a paired $t$ test.

Detection of cP450scc immunoexpression in cell cultures. To detect steroidogenic cells, a rabbit polyclonal Ab to P450scc (1:200, AB1244, Chemicon International, CA) was used. The staining protocol consists in the incubation with the primary $\mathrm{Ab}$ and then the staining itself (DAKO, Catalyzed Signal Amplification System K 1500). A minimum of 400 monolayer cells was counted. The percentage of positive brown-cell cytoplasm was calculated and compared in rhIGF-I stimulated and in basal condition cultures on d 6 (paired $t$ test).

Real-time RT-PCR of $3 \beta$ HSD mRNA. Total RNA, isolated from primary testicular cells cultures using TRIzol reagent, was reversely transcribed using M-MLV reverse transcriptase (Amersham Biosciences, Buenos Aires, Argentina) and oligo $(\mathrm{dT})_{15}$ primer (BiodynamIC SRL, Buenos Aires, Argentina) according to the supplier's protocol. Real-time PCR was performed using SYBR Green detection technology in a iCycler IQ5 Thermal Cycler (Bio-Rad Laboratories, Hercules, CA) for 40 cycles of $30 \mathrm{~s}$ at $95^{\circ} \mathrm{C}$, followed by $60 \mathrm{~s}$ at $66^{\circ} \mathrm{C}$. Primers for $3 \beta \mathrm{HSD}$ and $\beta$-actin amplification were previously published (22). A PCR supermix from Bio-Rad (IQ SYBR Green Supermix, catalog 170-8882) containing iTaq polymerase, $\mathrm{MgCl}_{2}$ dNTPs SYBR Green $\mathrm{I}$, and fluorescein was used. Primers were added to the reaction mix at a final concentration on $240 \mathrm{nM}$. Each assay included triplicates of cDNA for $3 \beta \mathrm{HSD}$ and for the reference gene, $\beta$-actin, no template control, and five serial dilutions of cDNA pooled from all treatments for $3 \beta \mathrm{HSD}$ and for $\beta$-actin, to calculate the corresponding amplification efficiency $(E=10-$ $(1 / b)-1 ; b$ is the regression coefficient). Ct for each reaction was automatically determined using the accompanying iCycler IQ5 software. The Ct values for each set of three reactions were averaged for all subsequent calculations. As the amplifications efficiencies of $3 \beta \mathrm{HSD}$ and $\beta$-actin genes were comparable, relative expression levels were calculated as $2-($ meanCt $3 \beta \mathrm{HSD}-$ meanCt $\beta$-actin) using $\beta$-actin as an endogenous control gene. The standard deviation (SD) of each triplicate sample was calculated from the SD of the $3 \beta \mathrm{HSD}$ and $\beta$-actin values using the following formula: $\mathrm{DS}_{\text {sample }}=\sqrt{ } \mathrm{DS}_{3 \beta \mathrm{HSD}}{ }^{2}+\mathrm{DS}_{\beta \text {-action }}{ }^{2}$. Data were analyzed using the paired $t$ test.

\section{RESULTS}

IGF-I, IGF-II, IGFR, IR, and GHR immunoexpression in testicular cells of different age Grs. Table 1 summarizes the quantitative estimation of the immunoexpression of IGF-I, 
Table 1. Immunolocalization and expression of IGF-I, IGF-II, $I G F R, I R$, and $G H R^{*}$

\begin{tabular}{cllll}
\hline Cell type & Marker & Gr1 & Gr2 & Gr3 \\
\hline Interstitial cell & IGF-I & $+/-$ & $+/-$ & $+/-$ \\
& IGF-II & + & $+/-$ & $+/-$ \\
& IGFR & + & + & $+/-$ \\
& IR & + & + & + \\
\multirow{5}{*}{ Leydig cell } & GHR & - & $+/-$ & - \\
& IGF-I & - & - & No $\dagger$ \\
& IGF-II & +++ & +++ & No \\
& IGFR & + & $+/-$ & No $\dagger$ \\
& IR & $+/-$ & ++ & No $\dagger$ \\
Peritubular cell & GHR & - & + & No \\
& IGF-I & - & - & - \\
& IGF-II & - & - & - \\
& IGFR & - & - & - \\
& IR & - & $+/-$ & - \\
& GHR & - & - & - \\
\hline
\end{tabular}

$*$ A mean of $<1 \%$ was considered as negative $(-), \leq 1$ to 5 as $+/-, \leq 5$ to 20 as,$+ \leq 20$ to 35 as ++ , and $\leq 35$ to 50 as +++ .

$\dagger$ No LC in Gr3.

IGF-II, IGFR, IR, and GHR in ICs and LCs of the testis in each prepubertal Gr, and Figure 1 shows representative microphotographs of different samples. IGF-I was barely detectable in ICs and LCs in all age Grs studied (Fig. $1 A 1$ and $A 2$, $A 2-L C$ ). IGF-II was barely detected in ICs of $\mathrm{Gr} 2$ and $\mathrm{Gr} 3$ but the intensity was higher in Gr1 (Table 1 and Fig. 1B1, B2). Remarkably, very strong immunostaining of IGF-II was detected in LCs of Gr1 and Gr2 (Table 1 and Fig. 1B2-LC). Moderate staining of IGFR was observed in ICs and LCs of Gr1 but it decreased in LCs of Gr2 and ICs of Gr3 (Table 1 and Fig. $1 C 1, C 2$, and $C 2-L C$ ). Moderate IR immunostaining was detected in ICs of the three age Grs. In LCs of Gr1, occasional staining of IR was found, whereas strong staining was observed in LCs of Gr2 (Table 1 and Fig. $1 D 1, D 2$, and $D 2-L C$ ). GHR was not detected in ICs and LCs of Gr1. However, in Gr2, staining was observed barely in ICs (Table 1), whereas moderate staining was found in LCs (Table 1 and Fig.
$1 E 2-L C)$. No positive staining in any of the five immunomarkers was observed in peritubular cells, except for IR in Gr2.

Effect of rhIGF-I on testicular somatic cell cultures. In primary cell cultures from human prepubertal testis corresponding to $\operatorname{Gr} 1(n=7)$ and to $\mathrm{Gr} 2(n=8)$, AI was studied in basal conditions and under chronic rhIGF-I stimulation. Results are expressed as percent change of basal value. Under rhIGF-I stimulation, mean ( \pm SD) AI decreased to $43.8 \pm$ $4.66 \%$ of basal $(p<0.0001, n=15)$. A microphotography of apoptotic cells (Fig. 2) showed that, in basal conditions, brown staining of apoptotic nuclei is more prominent than under chronic rhIGF-I stimulation.

PI could be analyzed in four primary human testicular somatic cell cultures corresponding to $\operatorname{Gr} 1(n=1)$ and $\mathrm{Gr} 3$ $(n=3)$. Under rhIGF-I stimulation, mean $( \pm \mathrm{SD})$ PI increased to $203 \pm 11.0 \%$ of basal value $(p<0.001, n=4)$.

The effect of rhIGF-I on $\mathrm{T}$ secretion in primary somatic cell cultures from human prepubertal testis corresponding to $\mathrm{Gr} 1$ $(n=5), \operatorname{Gr} 2(n=8)$, and $\operatorname{Gr} 3(n=6)$ is also shown in Figure 2. Under rhIGF-I stimulation, mean ( \pm SE) T secretion to the medium increased to $400 \pm 58.9 \%$ of basal $(p<0.0001$, $n=19)$. Data for individual Grs were $498 \pm 67.5,439 \pm 28.7$, and $267 \pm 11.5 \%$ of basal for Gr1, Gr2, and Gr3, respectively.

Immunoexpression of P450scc was investigated in basal conditions and under rhIGF-I stimulation (Fig. 2). In four primary human testicular somatic cell cultures corresponding to $\mathrm{Gr} 1(n=2)$ and $\mathrm{Gr} 2(n=2)$, mean $( \pm$ SE) P450scc immunoexpression under chronic rhIGF-I stimulation increased to $1440 \pm 405 \%$ of basal value $(p<0.05, n=4)$. Relative expression levels of $3 \beta \mathrm{HSD}$ mRNA, determined in one cell culture of Gr1 and in one of Gr3 showed 4.4- and 3.8-fold increments, under rhIGF-I stimulation.

\section{DISCUSSION}

A role for IGF-I in testicular growth and development has been demonstrated in rodents (23). The present study, carried
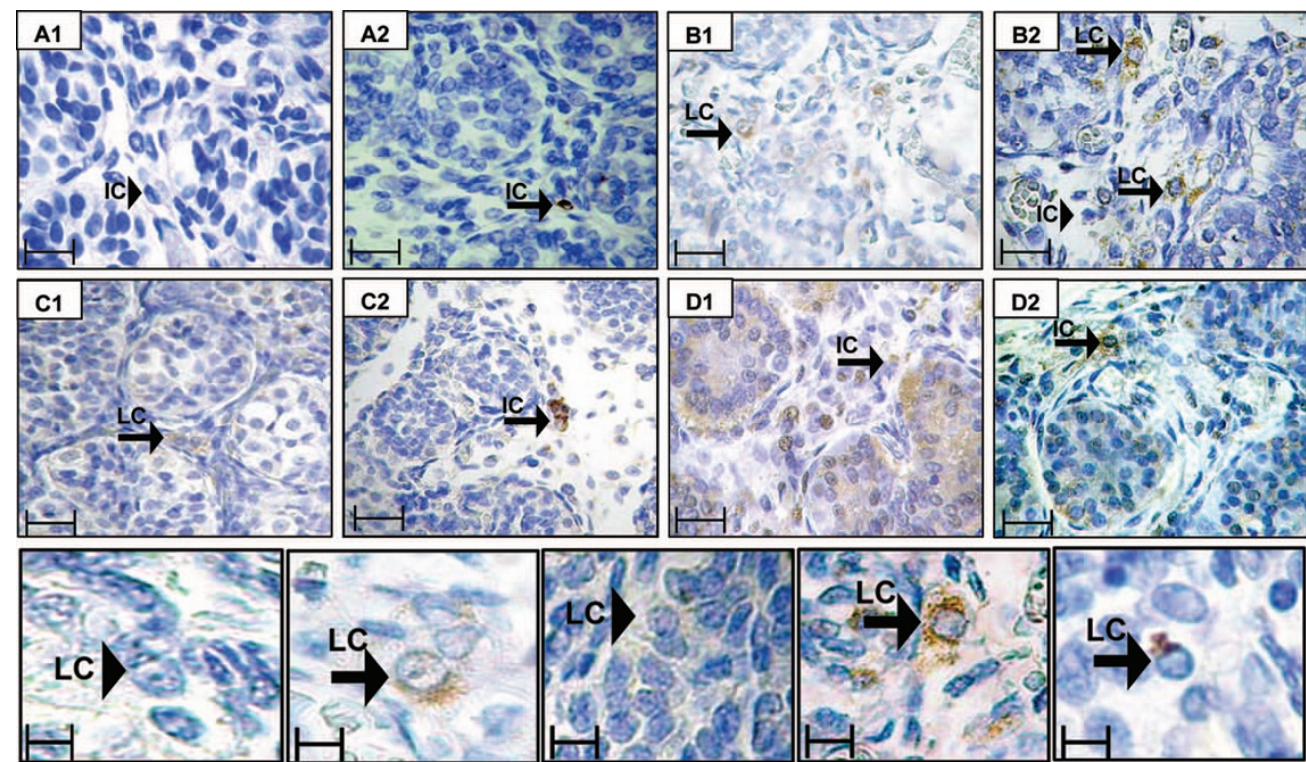

A2-LC

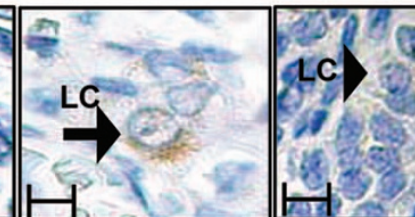

B2-LC
C2-LC

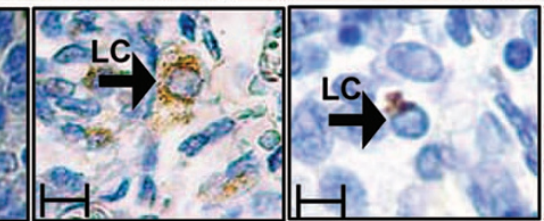

D2-LC

E2-LC
Figure 1. $A 1$, IGF-I-negative IC immunostaining is shown in a testis of Gr1. A2, One IGF-I-positive IC is observed in a testis of Gr2. B1, IGF-II immunostaining in a testis of Gr1. A few positive cells are observed in the interstitium, including one LC. B2, Similar to $B 1$, including two positive IGF-II LCs, and one negative IC, in a testis of Gr2. C1, IGFR immunostaining in a testis of Gr1. A positive $\mathrm{LC}$ is shown. $C 2$, Similar to $C 1$, showing one IGFR-positive IC, in a testis of Gr2. $D 1$, IR immunostaining in a testis of Gr1. A positive IC is shown. $D 2, \mathrm{Sim}$ ilar to $D 1$, showing one IR-positive IC, in a testis of Gr2. Lower row, individual LC immunostaining in testes of Gr2. $A 2-L C$, IGF-I. $B 2-L C$, IGF-II. $C 2$ $L C$, IGFR. D2-LC, IR. E2-LC, GHR. Scale bar: $20 \mu \mathrm{m}$. Arrows point out to positively stained cells whereas arrowheads to negatively stained cells. 

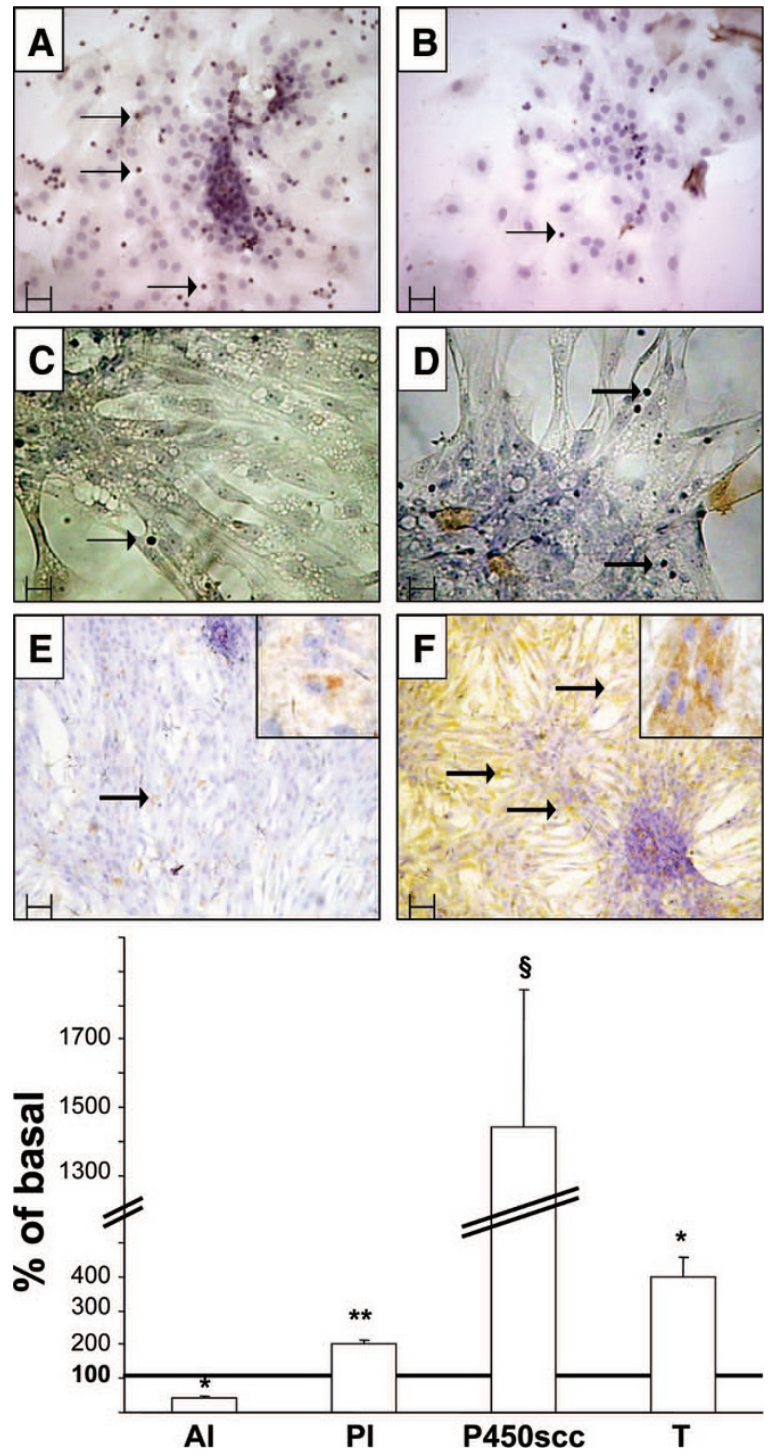

Figure 2. Primary cell culture of testicular cells (d 6), in the presence and absence of rhIGF-I $(50 \mathrm{ng} / \mathrm{mL})$ for $4 \mathrm{~d}$. TUNEL-positive cells $(A$ and $B)$, Ki67-positive cells $(C$ and $D)$, and P450scc-immunopositive cells ( $E$ and $F$ ). Scale bar: $20 \mu \mathrm{m}$. Basal condition, $A, C$, and $E$, IGF-I stimulation $(B, D$, and $F)$. Arrows point out to positively stained cells. Lower graph. Mean ( \pm SD) AI and PI, and mean $( \pm$ SE) P450scc immunocytochemistry and T secretion into culture medium is shown. Values are expressed as percent of basal determination. ${ }^{*} p<0.0001,{ }^{* *} p<0.001, \S p<0.05$.

out in necropsy material, has the limitations inherent to the putative influence that the pathologic process previous to death might have on the maturational events of the testis. However, because the information available in humans is so scarce, we felt stimulated to carry out this study. In contrast to a previous report showing that some human adult LC express IGF-I (24), and to the findings in rat testes (25), we found that IGF-II rather than IGF-I was expressed in postnatal ICs and, particularly LCs, suggesting that IGF-II might represent the main IGF of the human neonatal and infantile testicular interstitium. Furthermore, cord blood concentrations of IGF-II are approximately 10 times higher than those of IGF-I (26), and serum IGF-II remains higher than IGF-I during infancy and early prepuberty (27). In agreement with the study of Sriraman and Jagannadha Rao (28), it could be proposed that
IGF-II, among others factors, might be involved in the repopulation of precursor LC before the postnatal testicular activation takes place.

Even though most of the physiologic functions of IGF-I are thought to occur via IGFR (29), surprisingly, in newborn testes only moderate staining of IGFR in ICs and LCs was observed, whereas during the postnatal activation period, poor expression was also found in LCs. It is interesting that, Colon et al. (16) recently found that both IGF-II and insulin phosphorylate/activate rat testis IGFR in the same manner as IGF-I, suggesting that all of these factors activate common signaling pathways in LCs.

LCs are known to possess receptors for insulin (29). In particular, it has been described that the A isoform of IR has high affinity for IGFs, mainly IGF-II (17) acting as an autocrine stimulator of tumor growth (30). Along this line, we detected moderate IR expression in ICs of the three age Grs studied, but strong staining in LCs. Accordingly, it has been proposed that LH might be a key modulator of LC IR $(31,32)$. Hence, the strong IR staining observed in LCs during the postnatal activation period might be secondary to LH stimulation in vivo. Even though in the present study, the expression of the two IR isoforms was not evaluated separately, it might be speculated that IGF-II binds to A isoform of IR to regulate proliferation and differentiation of human LC precursors.

GHR was also expressed in human LCs during the postnatal activation period. Although only a slight decrease in serum IGF-II levels is observed in GH-deficient patients (33), it could be postulated that $\mathrm{GH}$, among other factors, might regulate the expression of IGF-II in LCs.

Our in vitro functional studies in primary immature testicular somatic cell cultures showed that rhIGF-I was able to induce cell proliferation and decrease cell apoptosis, suggesting that IGFs might control the LC precursor pool. IGF-I rather than IGF-II was used in in vitro studies because it was not foreseen that IGF-II would be the predominant IGF in LCs. Hardy et al. (34) were the first to provide experimental evidence that androgens are required for the differentiation of LC precursors. Recently, we have proposed (18) that androgens secreted by remaining fetal LCs might modulate, along with other factors such as estrogens and the IGF system, the proliferation, migration, and differentiation of new infantile LCs.

Growth factors such as IGF and insulin through endocrine, autocrine, and paracrine regulatory events are known to play diverse roles in steroidogenesis $(16,23,35)$. Hence, it could be proposed that, in the absence of LH, IGFs, via IGFR and/or IR, might induce the synthesis of androgens in precursor LC fibroblast. In accordance with this proposal, we observed that $\mathrm{T}$ secretion increased significantly under chronic rhIGF-I stimulation in cultures, suggesting that, similar to animal models (36), IGFs regulate steroidogenesis in the human immature testis. Indeed, an elevation of StAR, P450scc and $17 \alpha$-hydroxylase mRNA expression and steroid synthesis has been reported in mouse LC (37). In agreement with these reports, our in vitro functional studies have also shown that IGF-I induced expression of P450scc protein and $3 \beta \mathrm{HSD}$ mRNA. Moreover, lack of an IGF-I/insulin response second- 
ary to the absence of functional receptors for these ligands has been reported in MA-10 cells (38). Therefore, it seems logical to propose that the steroidogenic potential of IGFs might be related to the relative abundance of receptors and receptorligand interactions.

In summary, our observations provide the first evidence that the GH/IGF system, mainly IGF-II via IR and IGFR, might be one of the factors involved in the induction of infantile LC differentiation in humans. GHR was only detected in LC during the postnatal activation period, opening the possibility of a direct effect of GH. In vitro functional studies showed that IGF-I regulates human immature testicular cell proliferation and apoptosis, as well as steroidogenesis, suggesting that the $\mathrm{GH} / \mathrm{IGF}$ axis might be involved in preserving precursor and immature LC pools, as well as local steroidogenesis, in human immature testes.

Acknowledgments. We thank D. Chirico for technical support and M. Sciara and C. Gonzalez for helpful assistance.

\section{REFERENCES}

1. Prince FP 2001 The triphasic nature of Leydig cell development in humans, and comments on nomenclature. J Endocrinol 168:213-216

2. Zimmermann S, Steding G, Emmen JM, Brinkmann AO, Nayernia K, Holstein AF, Engel W, Adham IM 1999 Targeted disruption of the Insl3 gene causes bilateral cryptorchidism. Mol Endocrinol 13:681-691

3. Codesal J, Regadera J, Nistal M, Regadera-Sejas J, Paniagua R 1990 Involution of fetal Leydig cell. An immunohistochemical, ultrastructural and quantitative study. J Anat 172:103-114

4. Prince FP 1984 Ultrastructure of immature Leydig cells in the human prepubertal testis. Anat Rec 209:165-176

5. Chemes H, Cigorraga S, Bergada C, Schteingart H, Rey R, Pellizzari E 1992 Isolation of human Leydig cell mesenchymal precursors from patients with the androgen insensitivity syndrome: testosterone production and response to human chorionic gonadotropin stimulation in culture. Biol Reprod 46:793-801

6. Ge RS, Dong Q, Sottas CM, Papadopoulos V, Zirkin BR, Hardy MP 2006 In search of rat stem Leydig cell: identification, isolation, and lineage-specific development. Proc Natl Acad Sci USA 103:2719-2724

7. Baker J, Hardy MP, Zhou J, Bondy C, Lupu F, Belleu AR, Efstratiadis A 1996 Effects of an IGF-I gene null mutation on mouse reproduction. Mol Endocrinol 10:903-918

8. Wang G, Hardy MP 2004 Development of Leydig cell in the insulin-like growth factor-I (IGF-I) knockout mouse: effects of IGF-I replacement and gonadotropic stimulation. Biol Reprod 70:632-639

9. Wang GM, O'Shaughnessy PJ, Chubb C, Robaire B, Hardy MP 2003 Effects of insulin-like growth factor I on steroidogenic enzyme expression levels in mouse Leydig cells. Endocrinology 144:5058-5064

10. Rouiller-Fabre V, Lecerf L, Gautier C, Saez JM, Habert R 1998 Expression and effect of insulin-like growth factor I on rat fetal Leydig cell function and differentiation. Endocrinology 139:2926-2934

11. Rosenfeld RG, Rosenbloom AL, Guevara Aguirre J 1994 Growth hormone (GH) insensitivity due to primary GH receptor deficiency. Endocr Rev 15:369-390

12. Laron Z 1999 Natural history of the classical form of primary growth hormone (GH) resistance (Laron Syndrome). J Pediatr Endocrinol Metab 12:231-249

13. Zipf WB, Payne AH, Kelch RP 1978 Prolactin, growth hormone, and luteinizing hormone in the maintenance of testicular luteinizing hormone receptors. Endocrinology 103:595-600

14. Kanzaki M, Morris PL 1999 Growth hormone regulates steroidogenic acute regulatory protein expression and steroidogenesis in Leydig cell progenitors. Endocrinology 140:1681-1686

15. Harvey S, Baudet ML, Murphy A, Luna M, Hull KL, Aramburo C 2004 Testicular growth hormone $(\mathrm{GH})$ : $\mathrm{GH}$ expression in spermatogonia and primary spermatocytes. Gen Comp Endocrinol 139:158-167
16. Colon E, Svechnikov KV, Carlsson-Skwirut C, Bang P, Soder O 2005 Stimulation of steroidogenesis in immature rat Leydig cell evoked by interleukin-1alpha is potentiated by growth hormone and insulin-like growth factors. Endocrinology 146:221-230

17. De Meyts P 2004 Insulin and its receptor: structure, function and evolution. Bioessays 26:1351-1362

18. Berensztein EB, Baquedano MS, Gonzalez CR, Saraco NI, Rodríguez J, Ponzio R, Rivarola MA, Belgorosky A 2006 Expression of aromatase, estrogen receptor alpha and beta, androgen receptor, and cytochrome P-450scc in the human early prepubertal testis. Pediatr Res 60:740-744

19. Berensztein EB, Sciara MI, Rivarola MA, Belgorosky A 2002 Apoptosis and proliferation of human testicular somatic and germ cells during prepuberty: high rate of testicular growth in newborns mediated by decreased apoptosis. J Clin Endocrinol Metab 87:5113-5118

20. Allred DC, Bustamante MA, Daniel CO, Gaskill HV, Cruz AB Jr 1990 Immunocytochemical analysis of estrogen receptors in human breast carcinomas. Evaluation of 130 cases and review of the literature regarding concordance with biochemical assay and clinical relevance. Arch Surg 125:107-113

21. Berensztein E, Saraco N, Belgorosky A, Rivarola MA 2000 Secretion of inhibin B by human prepubertal testicular cells in culture. Eur J Endocrinol 142:481-485

22. Kreuzer KA, Lass U, Landt O, Nitsche A, Laser J, Ellerbrok H, Pauli G, Huhm D, Schmidt CA 1999 Highly sensitive and specific fluorescence reverse transcriptionPCR assay for the pseudogene-free detection of $\beta$-actin transcripts as quantitative reference. Clin Chem 45:297-300

23. Spiteri-Grech J, Nieshlag E 1992 The role of growth hormone and insulin-like growth factor 1 in the regulation of male reproductive function. Horm Res 38:22-27

24. Vannelli BG, Barni T, Orlando C, Natali A, Serio M, Balboni CG 1988 Insulin-like growth factor-1 (IGF-1) and IGF-I receptor in human testis: an immunohistochemical study. Fertil Steril 49:666-669

25. Mendis-Handagama SM, Ariyaratne HB 2001 Differentiation of the adult Leydig cell population in the postnatal testis. Biol Reprod 65:660-671

26. Geary MP, Pringle PJ, Rodeck GH, Kingdom JC, Hindmarsh PC 2003 Sexual dimorphism in the growth hormone and insulin-like growth factor axis at birth. J Clin Endocrinol Metab 88:3708-3714

27. Juul A, Dalgaard P, Blum WF, Bang P, Hall K, Michaelsen KF, Muller J, Skakkebaek NE 1995 Serum levels of insulin-like growth factor (IGF)-binding protein 3 (IGFBP-3) in healthy infants, children, and adolescents: the relation to IGF-I, IGF-II, IGFBP-1, IGFBP-2, age, sex, body mass index, and pubertal maturation. J Clin Endocrinol Metab 80:2534-2542

28. Sriraman V, Jagannadha Rao A 2004 Evaluation of the role of FSH in regulation of Leydig cell functions during different stages of its differentiation. Mol Cell Endocrinol 224:73-82

29. Lin T, Haskell J, Vinson N, Terracio L 1986 Characterization of insulin and insulin like growth factor-1 receptors of purified Leydig cells and their role in steroidogenesis in primary culture: a comparative study. Endocrinology 119:1641-1647

30. Sciacca L, Constantino A, Pandini G, Mineo R, Frasca F, Scalia P, Sbraccia P, Goldfine ID, Vigneri R, Belfiore A 1999 Insulin receptor activation by IGF-II in breast cancers: evidence for a new autocrine/paracrine mechanism. Oncogene 18:2471-2479

31. Saucier J, Tremblay RR, Dube JY 1983 Changes in insulin binding in rat testis following testosterone and gonadotrophins administration. J Recept Res 3:439-450

32. Julie PM, Arunakaran J, Malini T, Balasubramanian K 2003 The role of luteinizing hormone and prolactin in the regulation of insulin receptor in Leydig cells of the adult rat. Endocr Res 29:327-341

33. Ferrante E, Giavoli C, Porretti S, Vassallo E, Ronchi CL, Lania AG, Beck-Peccoz P, Spada A 2006 Evaluation of the components of the insulin-like growth factors system in GH-deficient adults: effects of twelve-month rhGH treatment. Horm Metab Res 38:352-355

34. Hardy MP, Kelce WR, Klinefelter GR, Ewing LL 1990 Differentiation of Leydig cell precursors in vitro: a role for androgen. Endocrinology 127:488-490

35. Saez JM 1994 Leydig cells: endocrine, paracrine, and autocrine regulation. Endocr Rev 15:574-626

36. Manna PR, Chandrala SP, King SR, Jo Y, Counis R, Huhtaniemi IT, Stocco DM 2006 Molecular mechanisms of insulin-like growth factor-I mediated regulation of the steroidogenic acute regulatory protein in mouse Leydig cells. Mol Endocrinol 20:362-378

37. Villalpando I, Lopez-Olmos V 2003 Insulin-like growth factor I (IGF-I) regulates endocrine activity of the embryonic testis in the mouse. J Steroid Biochem Mol Biol $86: 151-158$

38. Pignataro OP, Ascoli M 1990 Studies with insulin and insulin-like growth factor-I show that the increased labelling of phosphatidylinositol-3,4-bisphosphate is not sufficient to elicit the diverse actions of epidermal growth factor on MA-10 Leydig tumor cells. Mol Endocrinol 4:758-765 